\title{
Local Spatial Autocorrelation Characteristics of Landsat TM Imagery of a Managed Forest Area
}

\section{by M. Wulder • B. Boots}

\section{RÉSUMÉ}

En télédétection, les paysages en continu sont échantillonnés en fonction d'une grille de pixels d'égale dimension et d'espacement régulier. Une conséquence de cette régularisation de surface est que les valeurs de pixels exhibent une autocorrélation spatiale positive. Ainsi, on peut considérer que l'étendue et la nature de l'autocorrélation spatiale constituent une caractéristique des données de télédétection utilisable en tant que source d'information. Toutefois, les mesures globales d'autocorrélation spatiale existantes fournissent peu de connaissances quant à cette caractéristique étant donné $q u$ 'elles résument en une seule mesure toutes les interrelations spatiales. Par contraste, la mesure des indicateurs locaux d'association spatiale (LISA, local indicators of spatial indicators) permet d'évaluer pour chaque pixel de l'image à la fois le degré de dépendance spatiale du pixel par rapport aux pixels voisins et l'amplitude des valeurs de variation dans le voisinage $d u$ pixel. Dans cette étude, on applique une mesure LISA, la mesure Getis $\left(G_{i}{ }^{*}\right)$, à des images Landsat TM d'une région forestière aménagée. On note des relations entre, d'une part, l'autocorrélation spatiale au plan local telle que mesurée par $\left(G_{i}^{*}\right)$ et, d'autre part, différentes bandes Landsat TM et différents types de couvert. De plus, l'information sur la dépendance spatiale est présentée dans le contexte des polygones d'inventaire forestier indiquant la présence d'hétérogénéité ou d'homogénéité spectrale à l'intérieur des polygones forestiers. Cette recherche exploratoire confirme que l'information sur la dépendance spatiale telle que dérivée de la mesure de $\left(G_{i}{ }^{*}\right)$ constitue une nouvelle source importante d'information spatiale pour l'évaluation des images numériques en milieu forestier

\section{SUMMARY}

In remote sensing, continuous landscapes are sampled into a grid of equally sized and regularly spaced pixels. One consequence of this surface regularization is that pixel values exhibit positive spatial autocorrelation. Accordingly, the extent and nature of spatial autocorrelation can be considered a characteristic of remotely-sensed data which may be exploited as an information source. However, existing global measures of spatial autocorrelation provide little insight into this characteristic since they summarize all spatial interrelationships in a single measure. In contrast, local indicators of spatial association (LISA) measures assess for each pixel in the image both the degree of spatial dependence with neighbouring pixels and the magnitude of variate values in the neighbourhood of the pixel. In this study, one such LISA statistic, the Getis statistic $\left(G_{i}{ }^{*}\right)$, is applied to Landsat TM imagery of a managed forest region. Relationships are found between local spatial autocorrelation as measured by $G_{i}{ }^{*}$ and different Landsat TM image bands and differing cover types. Further, the spatial dependence information is presented in the context of forest inventory polygons indicating the presence of spectral heterogeneity or homogeneity within forest polygon areas. This exploratory research confirms that spatial dependence information, as computed by $G_{i}{ }^{*}$, constitutes a valuable new source of spatial information for the assessment of digital imagery of forests.

- Mike Wulder is with the Canadian Forest Service of Natural Resources Canada at the Pacific Forestry Centre, 506 West Burnside Road, Victoria, BC, V8Z 1M5, Canada. Tel.: (250) 363-6090; Fax: (250) 363-0775, E-mail: mike.wulder@nrcan.gc.ca.

- Barry Boots is with the Department of Geography and Environmental Studies, Wilfrid Laurier University, Waterloo, Ontario N2L 3C5. 


\section{INTRODUCTION}

Tn general, spatial autocorrelation arises when the value of a variable $x$ recorded at a location on the Earth's surface is related to values of the same variable at nearby locations. Thus, the measurement of spatial autocorrelation involves the simultaneous consideration of both locational and attribute information (Goodchild, 1986). Positive spatial autocorrelation is said to occur when similar values of $x$ are found in spatial juxtaposition while negative spatial autocorrelation occurs when neighbouring values of $x$ are dissimilar. The degree of spatial autocorrelation is not independent of the scale at which the data are analyzed, with negative spatial autocorrelation being more sensitive to scale changes (Chou, 1991). Since remote sensing instruments typically sample continuous landscapes into a grid of equally sized and regularly spaced pixels (Jupp et al., 1988; Fisher, 1997), it is anticipated that there will be some degree of dependency among pixel values sampled from a forested surface, most likely in the form of positive spatial autocorrelation.

Information gleaned through the remote sensing of forests is dependent upon the spatial resolution of the data collected (Marceau et al., 1994). When the objects of interest are composed of a number of pixels the imagery is considered to be H-resolution; conversely, when multiple objects compose one pixel, the imagery is considered L-resolution (Woodcock and Strahler, 1987). In the case of Landsat TM imagery of a forested region, the data are L-resolution when the objects of concern are trees, yet H-resolution when interested in broad areas of similar forest conditions (areas often delineated as stands). When considering imagery in terms of forest stands, neighbouring Landsat TM pixels may be expected to display some degree of spatial dependence. One view of this spatial autocorrelation is to consider it as a source of nuisance and error which must be accounted for when classical statistical analyses involving the assumption of independence are applied to the data (Dobbertin and Biging, 1996). An alternative view is to consider the spatial autocorrelation as an image characteristic representing aspects of forest structure which may be exploited as an additional information source (Wulder and Boots, 1998).

As presented in the statistics literature, spatial autocorrelation is often measured using global statistics (Haining, 1990), which provide a single measure summarizing all the spatially referenced inter-relationships. However, such measures may prove unreliable if the nature and extent of spatial autocorrelation varies significantly over the study area. To remedy these concerns, local indicators of spatial association (LISA) have been developed (Anselin, 1995). A summary of the techniques commonly utilized for the assessment of autocorrelation in remote sensing applications, including joincounts, semivariance, and texture, is presented in Wulder and Boots (1998). Generally, the techniques normally applied in a remote sensing context yield summary values which enable the identification of distinctive regions of spatial dependency within the image. In contrast, LISA measures focus upon variations within the regions of spatial dependence. As such, LISA measures are especially useful in detecting distinct local clusters of values that may be hidden in a global index measure.
One set of LISA measures is the $G$ statistics developed by Getis and Ord (1992) and Ord and Getis (1995). In general, these measures evaluate the extent and nature of concentration in the values of a variable $x$ in the region under investigation. One such measure, the modified Getis statistic, denoted as $G_{i}^{*}$, achieves this by expressing the sum of the variate values within a specified distance of a particular observation $i$ as a proportion of the sum of the entire set of variate values. Getis (1994) has previously demonstrated the diagnostic potential of this statistic to identify significant spatial dependency in remotely sensed imagery. Processing of an entire image scene allows for the use of the statistic in a more exploratory manner. By providing each pixel with a spatial dependency value, based upon processing pixel neighbourhoods with a series of windows, a new layer of information is derived.

The aim of this paper is to uncover the manner in which local spatial autocorrelation characteristics indicate change over forested landscapes. Since such images are inherently spatially autocorrelated, we anticipate that examination of properties of local spatial dependence can provide insights into characteristics of image data not revealed by traditional image analysis techniques. We apply $G_{i}{ }^{*}$ to a Landsat TM scene collected over a forested landscape. The various land cover types present over the forested landscape will exhibit differing spectral response in the imagery. The differing spectral response related to the land cover and sensed by the Landsat image spectral bands are investigated in this study. Our results indicate a strong band and cover type dependence to levels of local spatial autocorrelation as measured by $G_{i}{ }^{*}$.

\section{Methodology}

\section{Study Area, Field, GIS, and Image Data}

The Fundy Model Forest is a 420,000 hectare working forest in southeast New Brunswick, Canada. The model forest is located in the Acadian forest region (Rowe, 1977) and is composed of a variety of broadleaf deciduous and coniferous species and includes a wide range of forest conditions with stand ages ranging from regeneration to old growth. The Acadian forest region is characterized by a wide variety of forest species. Coniferous tree species are predominantly jack pine (Pinus banksiana), white spruce (Picea glauca), balsam fir (Abies balsamea), and red spruce (Picea rubens). The predominant deciduous species are red maple (Acer rubrum) and white birch (Betula papyrifera), with stands also including beech (Fagus grandifolia), striped maple (Acer pensylvanicum), trembling aspen (Populus tremuloides), long tooth aspen (Populus grandidentata), and sugar maple (Acer saccharum) (Farrar, 1995). The study area was located near Sussex at $45.43 .00^{\circ}$ north and $65.31 .00^{\circ}$ west.

The Landsat TM image, which was acquired August 7, 1992, was geometrically corrected utilizing the PCI EASI/PACE (version 6.0.1) utility of GCP Works. Base maps (1:50,000) and GPS information were used as the ground control, resulting in a RMS accuracy of 0.125 pixels utilizing 25 ground control points and a first-order nearest neighbour resampling technique. 
To provide a spatial context for the image colour composite, image classification, and $G_{i}{ }^{*}$ values presented, we imported the current New Brunswick GIS forest inventory database. The polygon boundaries provided a context for the distribution of image classification and $G_{i}{ }^{*}$ values. The forest inventory information was derived from the interpretation of air photos (Gillis and Leckie, 1993). The forest inventory information generalized the landscape into approximately 144 different classes including vegetated and non-vegetated classes. The vegetated forest management units are based upon species assemblages (such as tolerant hardwoods, intolerant hardwoods, conifers, and mixed woods) and structural conditions present (such as development stage, crown closure, site index, and silvicultural treatments) (Anonymous, 1983).

\section{Multispectral Digital Image Classification}

A maximum likelihood classifier was selected for the multispectral digital image classification (Jensen, 1996). The goal of the classification was to accurately assign pixels to a limited number of classes. The classes defined for discrimination are: conifer, deciduous, mixed forest, nonvegetation, shrub (sparse vegetation), water, and null. An overall producer's accuracy of $97.23 \%$, with an average accuracy of $93.27 \%$, was achieved for the multispectral image classification (Congalton, 1991). The classification was supervised based upon high resolution casi data, field collected ground cover survey data, and forest development survey maps.

\section{Global Spatial Autocorrelation as Measured with Moran's I}

Global measures of spatial autocorrelation provide little information regarding the nature of the spatial dependency found. A high positive spatial autocorrelation is expected due to the regularized nature of remotely-sensed imagery. This assumption is tested with the global spatial autocorrelation measure Moran's $I$. Computation of Moran's $I$ is achieved by division of the spatial covariation by the total variation. For pixel data, Moran's $I$ values are in the range from approximately -1 to 1 , with positive signage representing positive spatial autocorrelation, negative signage representing negative spatial autocorrelation, and values approaching zero indicating a lack of spatial autocorrelation (Haining, 1990).

\section{Computation of $G_{i}^{*}$}

In contrast to global measures such as Moran's I, LISA measures evaluate the extent and nature of concentration in the values of a variable $x$ in a local region within the study area. The Getis statistics (Getis, 1994) achieve this by expressing the sum of the weighted variate values within a specified distance of a particular observation $i$ as a proportion of the sum of the variate values for the entire study area. This value can be compared with the statistic's expected value under an hypothesis of no local spatial autocorrelation to indicate if the degree of clustering of $x$ values in the vicinity of $i$ is greater or less than chance would dictate.
There are two versions of the Getis statistic, $G_{i}$ and $G_{i}{ }^{*}$. In the former, the value of $x$ at $i$ is excluded from the local sum, while in the latter it is included. $G_{i}^{*}$ seems more appropriate for remote sensing applications as it allows for the computation of the statistic with a window of user-defined dimensions and so it is this statistic which we describe below.

Formally, the statistic $G_{i}{ }^{*}(d)$ for some distance $d$ is defined (Getis and Ord, 1992) as

$$
G_{i}^{*}(d)=\sum_{j} w_{i j}(d) x_{j} / \sum_{j} x_{j},
$$

where $\left\{w_{i j}(d)\right\}$ is a spatial weights matrix. Here we consider symmetric binary weights, with ones assigned to all locations within distance $d$ of observation $i$, including $i$ itself (i.e., $w_{i i}=1$ ), and zero otherwise. In the remote sensing context, a window can be defined around an observation $i$ by specifying an appropriate value of $d$.

Ord and Getis (1995) provide steps to derive a standardized version of $G_{i}^{*}$ which are summarized in the context of application to remote sensing digital images by Wulder and Boots (1998). Here the fundamental stages of the computation of $G_{i}^{*}$ values are presented, beginning with the calculation of the global mean and variance of $x$ for the image as follows:

$$
\bar{x}=\sum_{j=1}^{n} x_{j} / n \text { and } s^{2}=\frac{\sum_{j=1}^{n} x_{j}{ }^{2}}{n-\bar{x}^{2}},
$$

where $n$ is the number of pixels in the entire image. The standardized version of $G_{i}^{*}$ is given by

$$
G_{i}^{*}(d)=\frac{\sum_{j} w_{i j}^{(d)} x_{j}-W_{i}^{*} \bar{x}}{s\left[W_{i}^{*}\left(n-W_{i}^{*}\right) /(n-1)\right]^{1 / 2}},
$$

where $W_{i}^{*}=\Sigma_{j} w_{i j}(d)$. The values of $G_{i}^{*}$ given by Equation 3 are in standard normal form (z-score). Griffith et al. (1996) suggest that if a minimum of eight values are used for the computation of $G_{i}^{*}$, the resultant distribution of $G_{i}{ }^{*}$ values is normal. In consideration of remotely-sensed imagery, the $G_{i}{ }^{*}$ values measure the extent to which a pixel is surrounded by a cluster of high or low values of a particular variable, such as image digital number (DN) values. High $G_{i}^{*}$ values denote a cluster of high DN values; low $G_{i}^{*}$ values denote a cluster of low DN values. In addition, computing $G_{i}{ }^{*}$ within a series of increasing windows and noting the distance at which the largest absolute $G_{i}{ }^{*}$ value occurs allows for an assessment of the size of the region of association around an individual pixel. A small window size (distance) indicates that spatial dependency is maximized within a very localized region while a large distance value indicates more spatially extensive spatial dependence. A weakness of the $G_{i}{ }^{*}$ statistic, which it shares with other LISA measures (Tiefelsdorf and Boots, 1997), is that it cannot be used to identify clustering of medium values since mid-range values of $G_{i}^{*}$ (i.e., values around zero) can result from either this situation or an absence of clustering of similar variate values. 


\section{RESUltS AND DisCUSSION}

The image was assessed for both global and local spatial autocorrelation. The local spatial autocorrelation, as measured with the standardized version of $G_{i}^{*}$ (Equation 3 ), was assessed both between Landsat TM bands and by cover type within each band. Consideration of the spectral sensitivities of each of the Landsat TM bands provides for a greater understanding of the spatial dependency characteristics found in this study. Table 1 provides the wavelength ranges and expected characteristics of spectral response. The wavelengths of electromagnetic energy being sensed provide different information relating to the ground cover present; accordingly, it is necessary to be aware of what electromagnetic information is being sensed in each band.

A scale dependence of local spatial autocorrelation is also illustrated with the objects identified largely a function of the image spatial resolution. The relationship between objects identified and spatial resolution is illustrated by tree(s) level clustering at $\approx 1 \mathrm{~m}$ spatial resolution (Wulder, 1998a), stand level clustering at $30 \mathrm{~m}$ spatial resolution (present study), and landscape level clustering at $25 \mathrm{~km}$ spatial resolution (Derksen et al., 1998).

In Table 2 we present the Moran's $I$ values for Landsat TM 1 to 5, and 7. Landsat TM 6, which senses in the thermal IR, was not included due to a coarser spatial resolution and negligible spectral variability between pixels in this study area. All Landsat TM bands are found to have high positive Moran's $I$ values reflecting a strong presence of positive spatial autocorrelation. As the high positive autocorrelation was expected for the imagery, a means for exploiting this spatial information is indicated.

To enable the assessment of the relationship between each Landsat band and each of the dominant cover types with local spatial autocorrelation levels, a random sample of $G_{i}^{*}$ values was extracted. Determination of a sample size based upon a desired margin of error was undertaken to generate the random sample. The random sample of $G_{i}{ }^{*}$ values was based upon a sample size needed to achieve a sampling precision of 0.005 with $99 \%$

\begin{tabular}{|c|c|c|c|c|}
\hline \multicolumn{5}{|c|}{$\begin{array}{l}\text { Table } 1 . \\
\text { Landsat TM wavelengths and band characteristics } \\
\text { (summarized from Avery and Berlin, 1992, p. } 140 \text { to 142). }\end{array}$} \\
\hline TM band & $\begin{array}{l}\text { Wavelength } \\
\text { Range }(\mu \mathrm{m})\end{array}$ & $\begin{array}{l}\text { Spectral } \\
\text { Location }\end{array}$ & $\begin{array}{c}\text { Spatial } \\
\text { Resolution (m) }\end{array}$ & Characteristics \\
\hline 1 & $0.45-0.52$ & Blue-green & 30 & $\begin{array}{l}\text { water penetration, differentiates between vegetated and non- } \\
\text { vegetated }\end{array}$ \\
\hline 2 & $0.52-0.60$ & Green & 30 & visible vegetation features \\
\hline 3 & $0.63-0.69$ & Red & 30 & discerning between vegetation and soil \\
\hline 4 & $0.76-0.90$ & Near IR & 30 & $\begin{array}{l}\text { discrimination of differing vegetation and varieties and } \\
\text { conditions }\end{array}$ \\
\hline 5 & $1.55-1.75$ & Mid IR & 30 & $\begin{array}{l}\text { measures changes in leaf-tissue water content which may be } \\
\text { related to differences between plant species or vigour }\end{array}$ \\
\hline 6 & $10.40-12.50$ & Thermal IR & 120 & $\begin{array}{l}\text { sensitive to surface temperature; useful for heat mapping } \\
\text { applications }\end{array}$ \\
\hline 7 & $2.08-2.35$ & Mid IR & 30 & $\begin{array}{l}\text { sensitive to moisture content variation in both vegetation and } \\
\text { soils }\end{array}$ \\
\hline
\end{tabular}

\begin{tabular}{|c|c|c|c|c|c|c|}
\hline \multicolumn{7}{|c|}{$\begin{array}{l}\text { Table } 2 \text {. } \\
\text { Summary of Moran's } I \text { and Getis statistic values by } \\
\text { Landsat TM band for the } 300 \text { pixel sample of the processed imagery. }\end{array}$} \\
\hline & TM1 & TM2 & TM3 & TM4 & TM5 & TM7 \\
\hline Moran's I & 0.75 & 0.81 & 0.82 & 0.84 & 0.88 & 0.86 \\
\hline \multicolumn{7}{|c|}{ Getis statistic summary values } \\
\hline median & -0.082 & -0.112 & -0.220 & 0.027 & -0.100 & -0.196 \\
\hline mean & 0.057 & 0.044 & 0.034 & -0.006 & 0.022 & 0.030 \\
\hline $\min$ & -0.577 & -0.932 & -0.721 & -2.526 & -1.471 & -1.180 \\
\hline $\max$ & 2.158 & 2.605 & 3.363 & 0.955 & 2.121 & 3.340 \\
\hline range & 2.735 & 3.537 & 4.084 & 3.481 & 3.592 & 4.520 \\
\hline st. dev & 0.470 & 0.635 & 0.664 & 0.469 & 0.694 & 0.729 \\
\hline
\end{tabular}


confidence for the $G_{i}{ }^{*}$ values. The largest sample size needed for the six bands was 179 . Accordingly, a sample size of 300 was extracted to ensure translation of the original spatial correlation to the random sample (Moore and McCabe, 1993, p. 438).

Table 2 also contains the summary statistics for the $G_{i}{ }^{*}$ values for each Landsat TM band. The distribution of standardized $G_{i}^{*}$ values for each band is slightly skewed, as demonstrated by the difference between the median and the mean. The absolute maximum values of $G_{i}{ }^{*}$ found in each Landsat TM band relate an extreme level of local spatial autocorrelation. A wavelength dependence to the level of local spatial autocorrelation is also demonstrated in Table 2. The spectral band dependence to autocorrelation is based upon the dominant reflectance characteristics of the scene within the wavelength range represented by that band.

The band and species dependence to the distribution of $G_{i}{ }^{*}$ values is presented graphically with box plots in Figure 1. Trends are shown with the highest positive $G_{i}^{*}$ values for the most highly reflective surface cover types in the classification and the lowest $G_{i}^{*}$ values for the surface cover types with the least reflectance. Differences in level of local spatial autocorrelation are apparent both within class as the Landsat band is changed and between classes processed with the same Landsat band. The deciduous class demonstrates changes in local spatial autocorrelation tendencies with change in wavelength properties. The Landsat TM band 3 demonstrates a tendency toward clustering of low values. In the IR band of TM 4, higher standardized values are demonstrated due to clustering of higher DNs, especially in the deciduous class. The clustering of high DNs is especially prevalent in the nonvegetation and shrub cover classes, with the exception of shrub in TM 4. The mixed class is a combination of conifer and deciduous species resulting in less extreme clustering than that found in the conifer or deciduous classes. The inclusion of coniferous species in the mixed class results in lower reflectance and a greater degree of heterogeneity due to the complex stand structure, resulting in clusters of low DNs. The effect on local spatial autocorrelation due to lower reflectance and stand structure is further demonstrated for the conifer class.

As summary values do not sufficiently represent the spatial sensitivity of the $G_{i}^{*}$ values, in Figures $\mathbf{2}$ and $\mathbf{3}$ we graphically present a subset of the original Landsat TM image data, the image classification, and $G_{i}^{*}$ values computed on Landsat TM band 4. (Notation regions have been placed on Figures $\mathbf{2}$ and $\mathbf{3}$ to allow for comparison of the variation of information at consistent locations.) As noted in the Figure 2 legend, clusters of image digital number values and the strength of the association between neighbouring pixels are illustrated by the magnitude of the $G_{i}^{*}$ results. To demonstrate the complementarity of the spatial and spectral information sources, the $G_{i}^{*}$ values are presented in comparison to an image sample and a multispectral image classification. The spatial structure of the Landsat TM band $4 G_{i}^{*}$ values resemble the image classification which utilized three input bands to a maximum likelihood classifier (MLC). However, unlike the MLC, the calculation of $G_{i}{ }^{*}$ values within a window creates
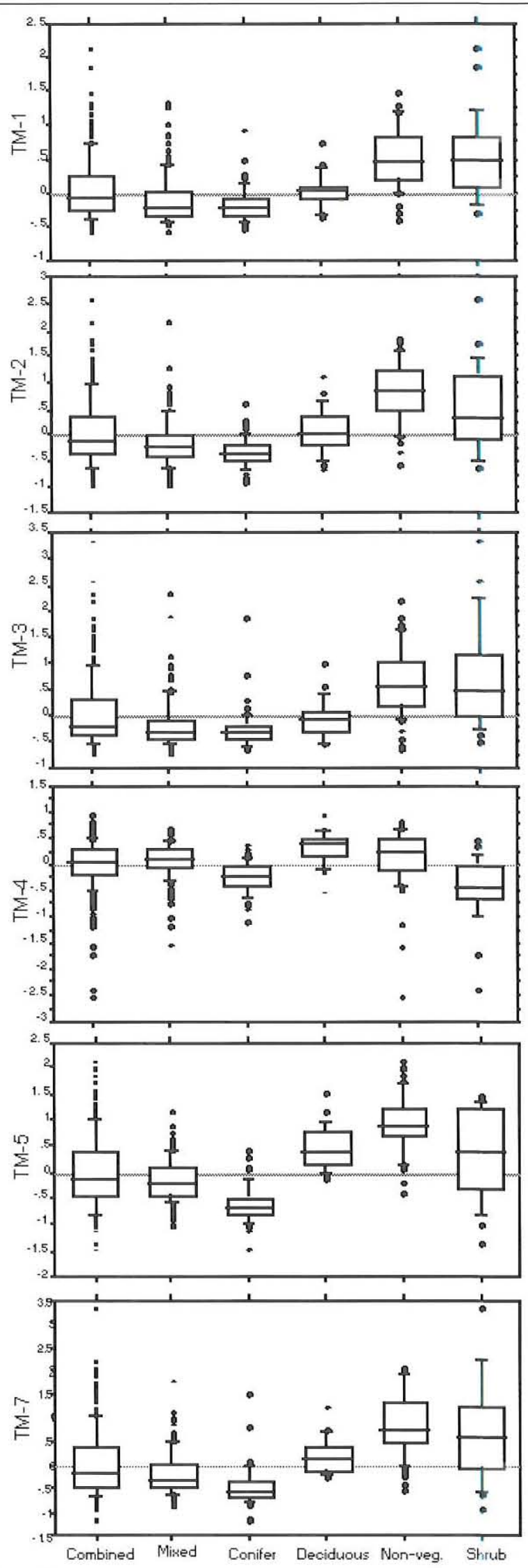

Figure 1.

Box plots of Getis statistic $\left(G_{i}^{*}\right)$ for all Landsat TM bands and cover types. 


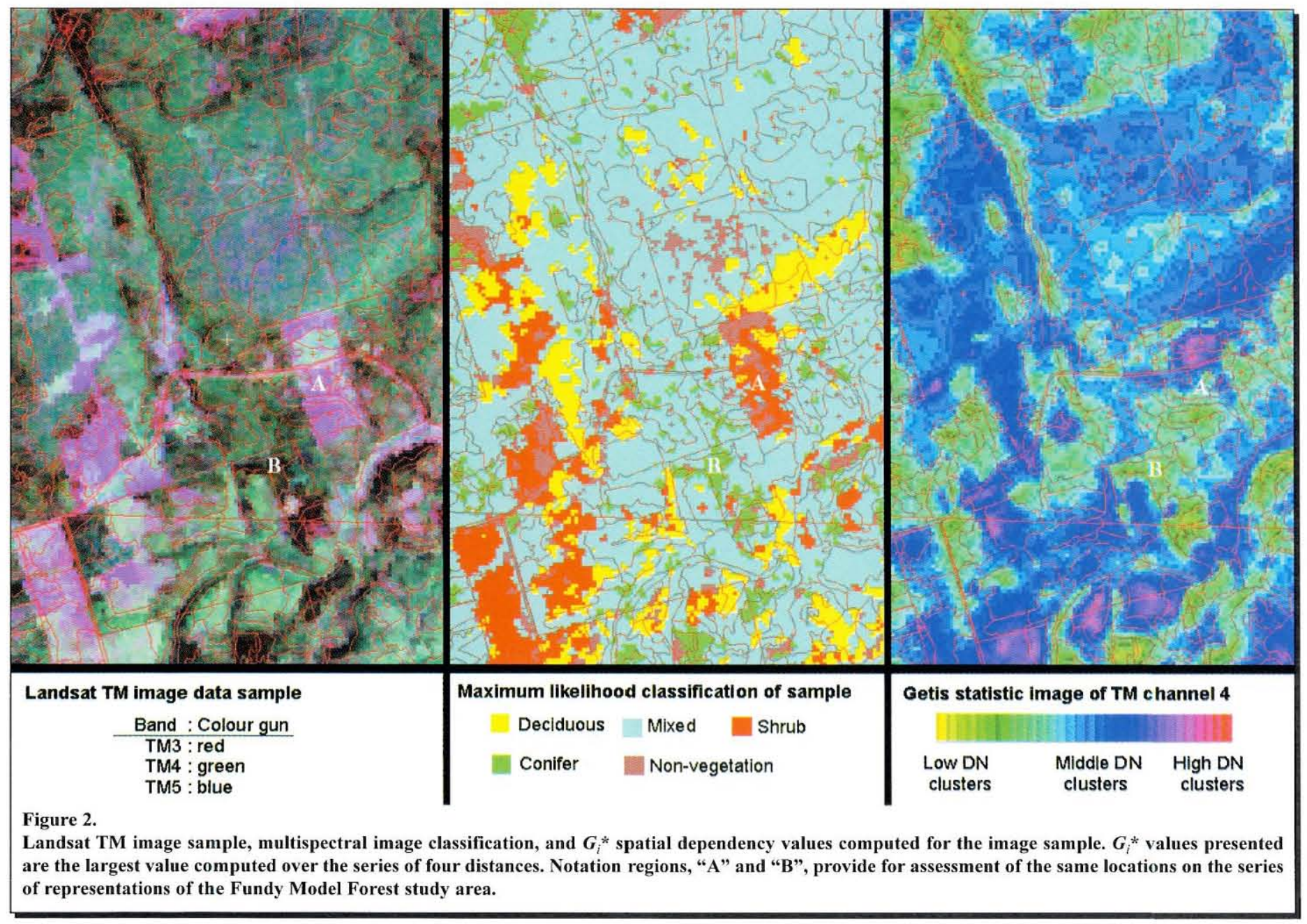

fuzzy boundaries between objects reflecting the subtle changes which occur in spectral values between image objects. Notation region A of Figure $\mathbf{2}$ is placed to indicate a harvested area. Harvested areas are often spectrally diverse in the near infrared (TM 4), with low reflectance post cutting and higher reflectance as regeneration takes place. The complexity of the TM 4 digital numbers is captured with the $G_{i}{ }^{*}$ values with the shrub area of the cut block exhibiting a clustering of high DN and the non-vegetated area of the cut showing a clustering of low values. The notation region B of Figure $\mathbf{2}$ is presented to indicate the clustering of relatively low TM 4 DNs indicating a coniferous area. Viewing of a coniferous area (notation region $\mathrm{B}$ ) through the transition of images, from composite to classification to spatial dependence image, indicates the sensitivity of the $G_{i}{ }^{*}$ values to the spatial extent of image objects. The cluster of low DNs illustrated in notation region $\mathrm{B}$ conform well to the polygon boundary. In other cases, the region of spatial dependence do not conform well to the polygon boundaries but extend to represent a larger region of association; notation region $\mathrm{C}$ of Figure 3 illustrates this case. The area classified as deciduous in the centre of the image sample is found within a mixed forest area. As noted, the calculation of $G_{i}^{*}$ values within a window creates fuzzy boundaries between objects reflecting the subtle changes which occur in spectral values between image objects. Viewing of notation region $\mathrm{C}$ on the $G_{i}{ }^{*}$ image of Figure 3 illustrates the strong spatial dependency for the homogenous cover-type that diminishes in strength as heterogeneity increases. Figures 2 and $\mathbf{3}$ also demonstrate how the $G_{i}^{*}$ values are of variable or object-resolution; the extent and intensity of the $G_{i}{ }^{*}$ values is a function of the spatial distribution of the spectral values related to that object. The deciduous area (notation area $\mathrm{C}$ ) with less distinct boundaries and subtle transition to neighbouring stands results in fuzzy boundaries to the $G_{i}{ }^{*}$ values. Notation region D of Figure 3 indicates a clustering of low digital numbers in relation to coniferous forest cover and the underlying drainage pattern. Patterns of spatial dependency are found for species of a classified image which indicate the potential for $G_{i}{ }^{*}$ as an ancillary data source or in the generation of fuzzy boundaries.

The spatial dependency objects, as illustrated by the $G_{i}{ }^{*}$ values, relate the information content present at the Landsat TM level of spatial resolution. The detail demonstrated in the forest stand polygon data is based upon air photo interpretation allowing for vegetation discrimination to indicate detailed characteristics such as leading and secondary species, crown closure class, and density (Gillis and Leckie, 1993). The agreement between the ground cover classes and spatial dependence values as different, yet complementary to, the 


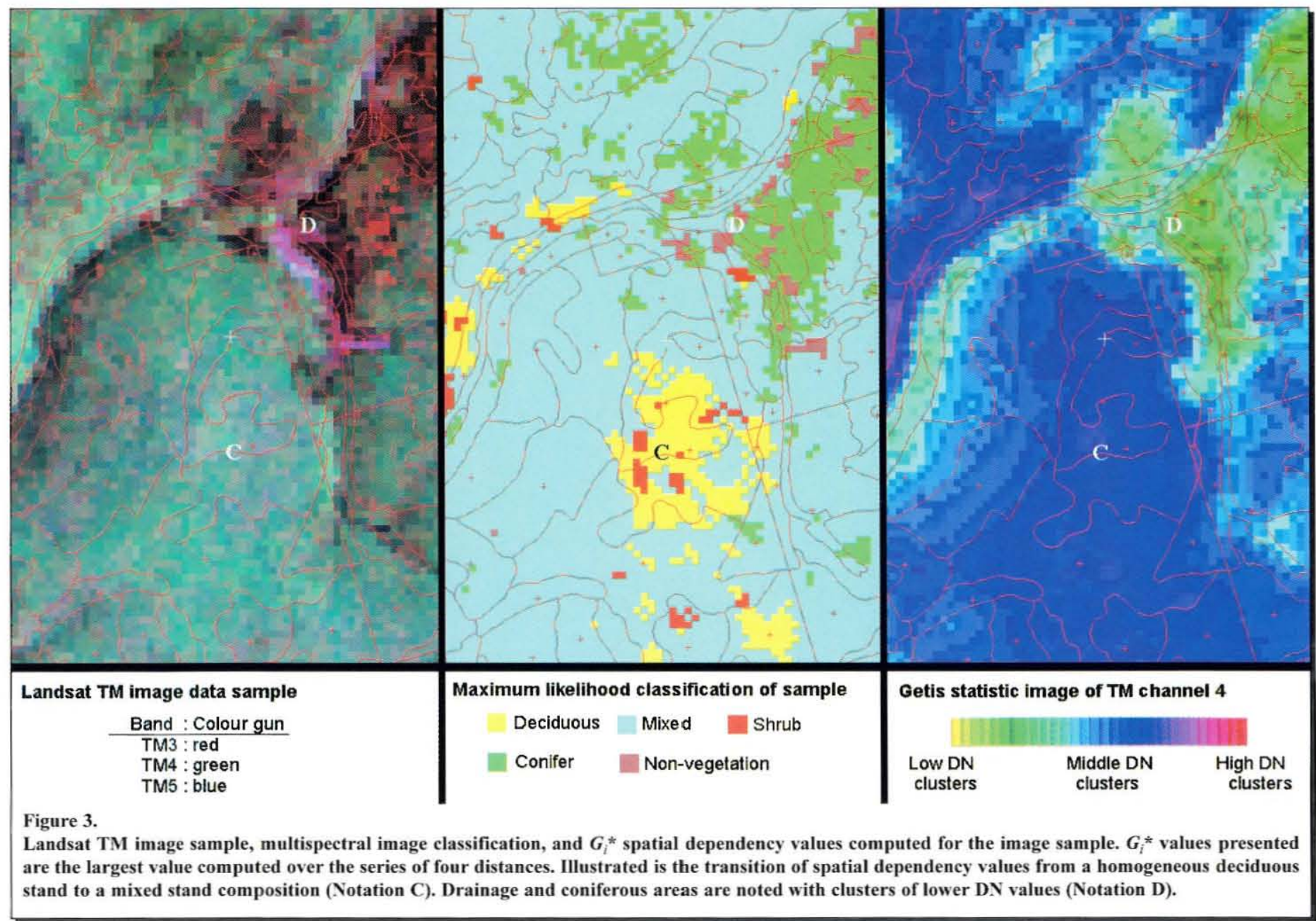

forest polygon data supports the findings of Franklin et al. (1997). Polygon information is normally intended for forest management activities, while the information present at the Landsat TM spatial resolution is often not of sufficient detail for management purposes. The extent of the spatial dependence objects generated indicate the utility of non-polygon based approaches when using remotely-sensed data for forest planning purposes, as demonstrated by Holmgren and Thuresson (1997). The spatial dependence data illustrates the presence of unique spectral objects within the forest polygon boundaries. This is expected based upon the delineation of forest polygon boundaries representing species assemblages, and has been previously investigated through the fusion of GIS and remotely-sensed data in the estimation of LAI (Wulder, 1998b). Knowledge of the distribution of spectrally unique objects, independent of forest stand polygons, facilitates generation of remotely-sensed values to act as model inputs. Visualization of the $G_{i}^{*}$ results illustrates that the results convey meaningful spatial information, demonstrating the potential of the Getis statistic in a forestry remote sensing context.

The distance values represent the size of the window in which computation of the $G_{i}^{*}$ statistic is maximized, where the level of spatial autocorrelation for that window size is greatest for the series of windows in which the $G_{i}^{*}$ statistic is computed
(Figure 4). Accordingly, low distance values indicate marked clustering of similar values, while high values represent a lesser clustering of similar values. A contrast of cover types demonstrates the theory; conifer stands with complex structure and variability in local reflectance require a number of iterations and a greater number of neighbours to be assessed to demonstrate a clustering of similar values; whereas, the shrub class is relatively uniform in reflectance, resulting in fewer pixels requiring assessment to demonstrate local spatial autocorrelation.

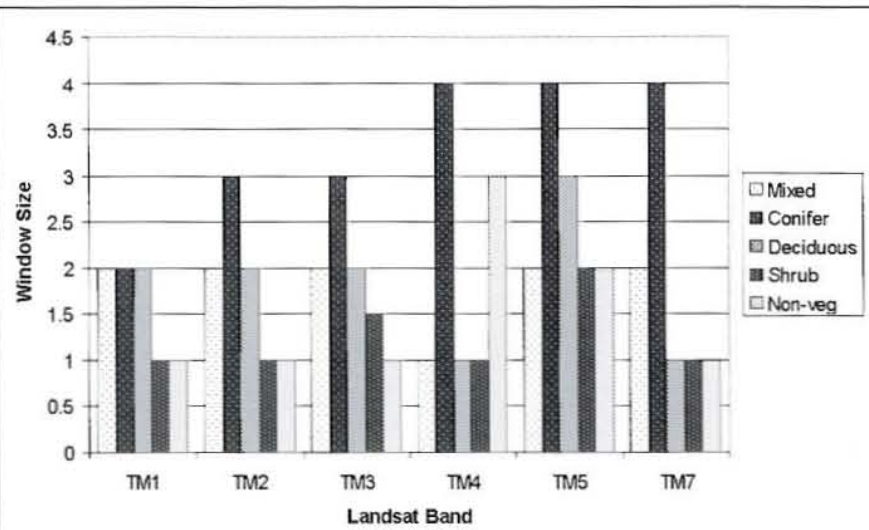

Figure 4.

Median distance in which Getis statistic is found to be at maximum. 
The exploratory nature of $G_{i}{ }^{*}$ has been demonstrated in the previous figures and tables, yet $G_{i}{ }^{*}$ may also be utilized in a diagnostic manner. Since the $G_{i}{ }^{*}$ values are z-score standardized, the significance of spatial autocorrelation on a pixel basis may be assessed. Table 3 denotes if there are $G_{i}{ }^{*}$ values found which are significant within a particular cover type or band. Values are considered significant at a $95 \%$ level if greater than absolute z-score of 1.96. Pixel locations exhibiting extreme spatial dependence (image spectral hotspots) may be identified through the analysis of significance of $G_{i}{ }^{*}$ values. As an absolute threshold, the significance may be altered depending on the level of spatial dependence that is desired for the representation of image spectral hotspots.

\begin{tabular}{|c|c|c|c|c|c|}
\hline \multicolumn{7}{|c|}{ Table 3. } \\
Significant $G_{i}{ }^{*}$ values for each band and class as a \\
demonstration of the diagnostic properties of $G_{i}{ }^{*}$. \\
+ denotes greater than 1.96, - denotes less than \\
$-\mathbf{1 . 9 6 ,} \bullet$ denotes insignificance).
\end{tabular}

\section{CONCLUSION}

A Landsat TM band and species dependence to the level of local spatial autocorrelation as measured by the $G_{i}{ }^{*}$ statistic is demonstrated in this study. $G_{i}{ }^{*}$ computation is an efficient approach to the assessment, generation, and utilization of spatial dependence information present based upon neighbouring pixel inter-relationships. LISA statistics, specifically the Getis statistic, provide values based on the spatial structure of digital images. The ability to assess the strength of inter-pixel relationships, as well as the magnitude of the autocorrelated data, may prove valuable when the values computed from semivariance, as a positive valued function, prove inadequate for a particular objective.

The computation of Moran's $I$ illustrated the presence of positive spatial autocorrelation in all image bands. This spatial autocorrelation may be considered as a source of error or it may be looked upon as an additional information source. In the case of the present study, the spatial autocorrelation is considered as a possible additional information source (such as in aiding image classification or in locating unique areas) and is investigated as such. Local spatial autocorrelation characteristics, in the form of the Getis statistic, were generated to explore the spatial autocorrelation characteristics present in the imagery in relation to a digital image classification and also in the context of forest inventory polygons. Differences in level of local spatial autocorrelation are demonstrated, through summary statistics, to be evident both within class as the Landsat band is changed and between classes processed with the same Landsat band. To show the spatial sensitivity of $G_{i}{ }^{*}$ values, a graphical comparison of an image colour composite, image classification, and values superimposed with forest stand polygon boundaries is presented. The comparison illustrated the relationship between the spatial structure of the Landsat TM band $4 G_{i}^{*}$ values to resemble the image classification which utilized three input bands to a maximum likelihood classifier (MLC). Due to the computation of the $G_{i}^{*}$ values within a window, fuzzy boundaries between objects emerge reflecting the subtle changes which occur in spectral values between image objects. The comparison also demonstrates how the $G_{i}{ }^{*}$ values are of variable or object-resolution. The extent of the spatial dependence objects generated indicate the utility of raster-based approaches when using remotely-sensed data for forest planning purposes (Holmgren and Thuresson, 1997) or for the generation of model inputs (Franklin et al., 1997). Visualization of the $G_{i}^{*}$ results illustrates that the results convey meaningful spatial information, demonstrating the potential of the Getis statistic in a forestry remote sensing context.

The distance values represent the size of the window in which computation of the $G_{i}^{*}$ statistic is maximized, where the level of spatial autocorrelation for that window size is greatest for the series of windows in which the $G_{i}^{*}$ statistic is computed. The distance values were found to vary by cover type indicating differences in the heterogeneity of digital numbers and the spatial extent of the objects within the cover type.

Future research initiatives are planned to assess issues such as the utility of LISA statistics in the assessment of locations of image heterogeneity for algorithm development and scaling, multi-temporal comparison of $G_{i}^{*}$ values (Derksen et al., 1998), image segmentation (Wulder, 1998a), creation of fuzzy boundaries, assessment of $G_{i}{ }^{*}$ as ancillary data in a maximum likelihood classification, and use of $G_{i}^{*}$ to assist in class signature development.

\section{ACKNOWLEDGEMENTS}

The authors thank Dr. Mike Lavigne of the Canadian Forest Service of Natural Resources Canada for provision of the Landsat TM data. Dr. Ellsworth LeDrew, of the Waterloo Laboratory for Earth Observations, is also gratefully acknowledged for advice and support provided to Mike Wulder for this research project and during his graduate studies at the University of Waterloo. Two anonymous reviewers are also thanked for their insights and keen attention to the content of the paper resulting in many helpful improvements. 


\section{REFERENCES}

Anonymous. (1983). "Forest Development Survey", Department of Natural Resources, Forest Management Branch, Fredericton, 21p.

Anselin, L. (1995). "Local Indicators of Spatial Association - LISA", Geographical Analysis, Vol. 27, No. 2, pp. 93-115.

Chou, Y.H. (1991). "Map Resolution and Spatial Autocorrelation". Geographical Analysis, Vol. 23, pp. 228-246.

Congalton, R. (1991). "A Review of Assessing the Accuracy of Classifications of Remotely Sensed Data", Remote Sensing of Environment, Vol. 37, pp. 35-46.

Derksen, C., Wulder, M., LeDrew, E., and Goodison, B. (1998). "Associations Between Spatially Derived Autocorrelation Patterns of SSM/IDerived Prairie Snow Cover and Atmospheric Circulation", Hydrological Processes, Vol. 12, pp. 2307-2316.

Dobbertin, M., and Biging, G. (1996). "A Simulation Study of the Effect of Scene Autocorrelation, Training Sample Size Method on Classification Accuracy", Canadian Journal of Remote Sensing, Vol. 22, No. 4, pp. 360-367.

Farrar, J. (1995). "Trees in Canada", Fitzhenry \& Whiteside Limited and the Canadian Forest Service of Natural Resources Canada, Ottawa, 502p.

Fisher, P. (1997). "The Pixel: A Snare and a Delusion", International Journal of Remote Sensing, Vol. 18, pp. 679-685.

Franklin, S., Lavigne, M., Deuling, M., Wulder, M., and Hunt, E.R. (1997) "Landsat Derived Forest Covertypes for Modelling Net Primary Productions", Canadian Journal of Remote Sensing, Vol. 23, No. 3, pp. 243-251.

Getis, A. (1994). "Spatial Dependence and Heterogeneity and Proximal Databases", Chapter 2, In Spatial Analysis and GIS, Ed. S. Fotheringham and P. Rogerson, Taylor \& Francis, London, 281p.

Getis, A., and Ord, J. (1992). "The Analysis of Spatial Association by Distance Statistics", Geographical Analysis, Vol. 24, No. 3, pp. 189-206.

Gillis, M., and Leckie, D. (1993). "Forest Inventory Mapping Procedures Across Canada", Forestry Canada, PNFI, Information Report PI-X-114, 79p.

Goodchild, M. (1986). "Spatial Autocorrelation", Concepts and Techniques in Modern Geography, Vol. 47, Geo Books, Norwich, 56p.

Griffith, P., Getis, A., and Griffin, E. (1996). "Regional Patterns of Affirmative Action Compliance Costs", The Annals of Regional Science, Vol. 30, 321-340.
Haining, R. (1990). "Spatial Data Analysis in the Social and Environmental Sciences", Cambridge University Press, Cambridge, 409p.

Holmgren, P., and Thuresson, T. (1997). "Applying Objectively Estimated and Spatially Continuous Forest Parameters in Tactical Planning to Obtain Dynamic Treatment Units”, Forest Science, Vol. 43, No. 3, pp. 317-326.

Jensen, J. (1996). "Introductory Digital Processing: A Remote Sensing Perspective", Prentice Hall; Englewood Cliffs, NJ, 316p.

Jupp, D., Strahler, A., and Woodcock, C. (1988). "Autocorrelation and Regularization in Digital Images: I. Basic Theory", IEEE Transactions on Geoscience and Remote Sensing, Vol. 26, No. 4, pp. 463-473.

Marceau, D., Howarth, P., Gratton, D. (1994). "Remote Sensing and the Measurement of Geographical Entities in a Forested Environment. 1. The Scale and Spatial Aggregation Problem", Remote Sensing of Environment, Vol. 49, pp. $93-104$

Moore, D., and McCabe, G. (1993). "Introduction to the Practice of Statistics", W. H. Freeman and Company, New York, 854p.

Ord, J., and Getis, A. (1995). "Local Spatial Autocorrelation Statistics: Distributional Issues and an Application", Geographical Analysis, Vol. 27, No. 4 , pp. 286-306.

Rowe, J. (1977). "Forest Regions of Canada", Environment Canada, Canadian Forest Service Publication No. 1300, Ottawa, Ontario, 172p.

Tiefelsdorf, M. and Boots, B. (1997). "A Note on the Extremities of Local Moran's $I_{i}$ 's and their Impact on Global Moran's I", Geographical Analysis, Vol. 29, pp. 248-257.

Woodcock, C., and Strahler, A. (1987). "The Factor of Scale in Remote Sensing", Remote Sensing of Environment, Vol. 21, pp. 311-322.

Wulder, M. (1998a). "Spatial Dependence in the Estimation of Forest Structural Parameters", Unpublished Ph.D. Dissertation, Department of Geography, University of Waterloo, Waterloo, Ontario, Canada, 249p.

Wulder, M. (1998b). "The Prediction of Leaf Area Index from Forest Polygons Decomposed through the Integration of Remote Sensing, GIS, UNIX, and C", Computers \& Geosciences, Vol. 24, No. 2, pp. 151-157.

Wulder, M., and Boots, B. (1998). "Local Spatial Autocorrelation Characteristics of Remotely Sensed Imagery Assessed with the Getis Statistic", International Journal of Remote Sensing, Vol. 19, No. 11, pp. 2223-2231. 